\title{
Priorities for the alpha-1 community: The physicians perspective
}

\author{
Sanjay Haresh Chotirmall*, Tomás Carroll, Muirne Spooner and \\ Noel Gerard McElvaney \\ Respiratory Research Division, Beaumont Hospital, Dublin, Ireland
}

\section{Introduction}

Alpha-1 antitrypsin (AAT) deficiency is a clinically under-recognized hereditary disorder with multi-system manifestations, most prominently in the lungs and liver. A rare skin manifestation is also described. The AAT protein is synthesized in the liver and to a lesser extent in macrophages and neutrophils. AAT is the physiological inhibitor of a variety of proteases most notably neutrophil elastase (NE). Unopposed, $\mathrm{NE}$ and other proteases attack the lung matrix causing structural damage and markedly impairing host defence. In the commonest form of AAT deficiency the mutated Z AAT is improperly folded, polymerises and aggregates in the liver. As a result less AAT is secreted into the bloodstream and gets to the lungs. This results in liver disease due to AAT aggregation in the liver and pulmonary damage due to the deficiency in the lung rendering it unable to protect against NE-mediated damage. In this review we will discuss AAT deficiency in detail, outlining the pathogenesis, and the clinical manifestations of the condition.

\section{The alpha-1 gene and subsequent deficiency disease state}

AAT deficiency was first described by Laurell and Eriksson in 1963 who noted a clinical link with emphysema [1]. Just over 6 years later Sharp et al. first associated the protein deficiency with liver disease [2].

Since then, our understanding has advanced significantly. The AAT gene, located on the long (q) arm of chromosome 14 is a member of the serpin gene family which encode a group of serine protease inhibitors. Inheritance is monogenic and autosomal co-dominant where products of both alleles are expressed. There are numerous AAT

\footnotetext{
${ }^{*}$ Corresponding author. E-mail: schotirmall@ @rcsi.ie.
} 
Table 1

Table showing genotype variants in alpha-1 antitrypsin protein level \& function

\begin{tabular}{|c|c|c|}
\hline Variant & Allele or mutation & \\
\hline Normal & $M$ & $\begin{array}{l}\text { Normal plasma levels }(>20 \mu \mathrm{mol} / \mathrm{L}) \\
95 \% \text { of alleles in Caucasian populations }\end{array}$ \\
\hline Deficient & $Z$ or $S$ & $\begin{array}{l}\text { Common deficiency variants: ' } Z \text { ' }(5-6 \mu \mathrm{mol} / \mathrm{L}) \& \\
\text { 'S' }(8-11 \mu \mathrm{mol} / \mathrm{L}) \text { plasma levels }\end{array}$ \\
\hline Null & $Q O_{\text {Lisbon, }}$ Thr68IIe exon II & $\begin{array}{l}\text { No detectable circulating protein; no associated liv- } \\
\text { er disease }\end{array}$ \\
\hline Dysfunctional & Met358Arg & $\begin{array}{l}\text { Unique Pittsburgh mutation (3): converts protein } \\
\text { into thrombin rather than elastase inhibitor }\end{array}$ \\
\hline
\end{tabular}

alleles, and their nomenclature is based on their migration on electrophoresis, with those exhibiting high isoelectric points being allocated letters from the beginning of the alphabet, and those with low isoelectric points conferred letters from the end of the alphabet. At least 100 alleles have been identified; however they can be widely classified into four main clinical groups, based on serum levels and function (Table 1).

Both null and dysfunctional mutations are rarely encountered in clinical practice with the majority of patients with AAT deficiency either homo- or heterozygous for ' $Z$ ' or ' $S$ ' variants which subsequently correlate with severity of pulmonary or hepatic manifestations of disease. The highest disease incidence is within Europe [4,5].

Base substitutions, in-frame and exon deletions and frame-shift mutations can all occur within the AAT gene. The most common and clinically important variants $(\mathrm{S}, \mathrm{Z})$ result from single amino acid substitutions: a valine for glutamate at position 264 (Glu264Val) in the case of the ' $S$ ' variant and lysine for glutamate at position 342 (Glu342Lys) for the ' $Z$ ' variant [6]. The $S$ protein is less polymerogenic than $Z$ and results in reduced accumulation of S AAT within hepatocytes, yielding a milder serum deficiency. However, if the $\mathrm{S}$ variant is inherited with the rapidly polymerising $\mathrm{Z}$ variant, the two forms interact within hepatocytes, forming inclusions and in some cases, cirrhosis [7-10].

Hepatic polymerisation of Z AAT results in minimal secretion into the bloodstream and hence the lung. Consequently, a pulmonary protease-antiprotease imbalance occurs where proteases such as NE are relatively unopposed in causing lung destruction and hampering immune responses by effects on complement receptors [11, 12], immunoglobulins [13], ciliary motility [14], and antiproteases such as secretory leucoprotease inhibitor (SLPI) and elafin $[15,16]$. The polymerisation of Z AAT in the liver also goes some way to explaining liver disease associated with the condition. Normally cells have a mechanism by which abnormally folded proteins are recognised and removed. In AAT deficiency there is an imbalance between protein folding load and the cell's ability to process this load. The result is endoplasmic reticulum (ER) stress which manifests in a variety of individual but not exclusive intracellular responses including the ER overload response (EOR), the unfolded protein response (UPR) and apoptosis [17]. 


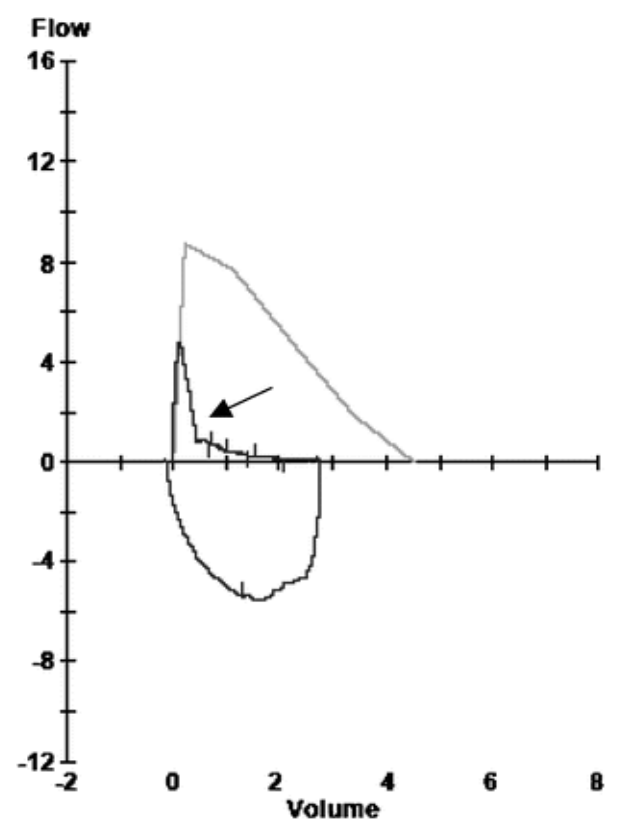

Fig. 1. Flow-volume loop of a patient with Alpha-1 antitrypsin deficiency. Coving of the expiratory portion of the curve is seen (arrow), reflecting flow limitation. A normal expiratory curve is also shown.

\section{Clinical manifestations of AAT deficiency lung disease}

The hallmark of AAT pulmonary disease is early onset panacinar emphysema in a predominantly basal distribution $[18,19]$. Obstructive lung disease presents at a mean age of 32 to 41 in subjects with a current or previous history of smoking [2024]. In a study of $246 \mathrm{PI} * \mathrm{ZZ}$ individuals, chronic obstructive pulmonary disease (COPD) was present in $74.8 \%$ at a median age of 52 years [25]. True natural history of this condition remains uncertain; many individuals with AAT deficiency remain undiagnosed or misdiagnosed as non-hereditary emphysema. Most individuals with AAT deficiency have a smoking history (NHLBI Registry). Smoking is estimated to shorten survival of AAT-deficient individuals by up to 20 years [20].

The National Heart, Lung and Blood Institute Registry (NHLBI) of individuals with AAT deficiency utilised standardized symptom questionnaires to quantify symptom frequency. Exertional dyspnoea was predominant (84\%), followed by self-reported wheezing $(65 \%)$, cough with phlegm $(50 \%)$ and coughing alone $(42 \%)$. Frequency of wheeze is important as $35 \%$ of subjects self-reported a history of asthma, while $50 \%$ had a significant bronchodilator-associated reversibility of airflow obstruction on serial testing [26]. Eden et al. assessed for the presence of asthma through wheezing, bronchodilator responsiveness, atopy, and increased serum IgE. They demonstrated the presence of three or more of these markers in $22 \%$ of AAT-deficient patients compared with $5 \%$ of COPD patients without AAT deficiency [27]. 


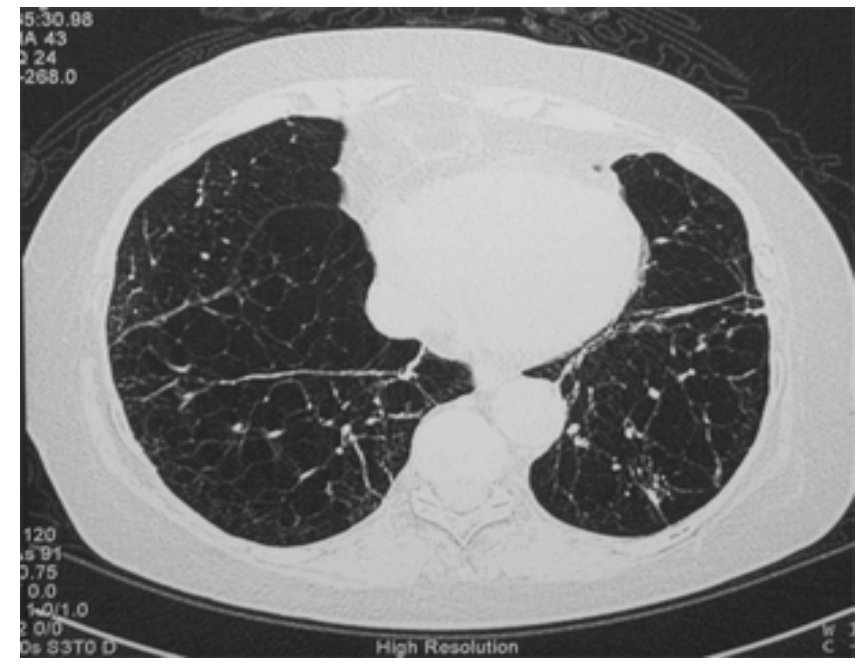

Fig. 2. High Resolution Computed Tomography (HRCT) of lung bases from patient with Alpha-1 antitrypsin deficiency. Widespread emphysematous changes are seen bilaterally.

Pulmonary function in established disease shows decreased expiratory flow rates $\left(\mathrm{FEV} 1 \&, \mathrm{FEF}_{25-75}\right)$ but preserved forced vital capacity (FVC). Flow volume curves show "classic coving" on expiration (Fig. 1).

Plain chest radiography (CXR) in early disease shows minimal change. Changes are seen earlier and are more easily quantified on computed tomography (CT) scans of the thorax (Fig. 2). There has been an increased use of CT scanning in AAT deficiency for two main reasons; to detect early disease before appreciable loss of lung function and to assess efficacy of therapeutic interventions such as augmentation therapy. This has led to the detection of other associated lung conditions such as bronchiectasis. Guest at al. [28] demonstrated that in an AAT deficiency population, radiological features consistent with bronchiectasis were observed in $41 \%$. King et al. [29] demonstrated a similar prevalence of bronchiectasis (43\%). An early series however, by Larsson et al. [21] showed that bronchiectasis was present in just $11.3 \%$ of $246 \mathrm{PI} * \mathrm{Z}$ homozygotes investigated.

Arterial blood gases $(\mathrm{ABG})$ show normoxia or hypoxia at rest although hypercapnia is seen in advanced disease associated with markedly decreased FEV1 [26].

\section{Clinical manifestations of AAT deficiency liver disease}

Sharp and colleagues [2] first described cirrhosis in AAT deficiency in 10 children from six families and later reported intra-hepatocyte periodic acid-Schiff diastaseresistant inclusions, which occur owing to polymer formation of Z AAT in the ER 


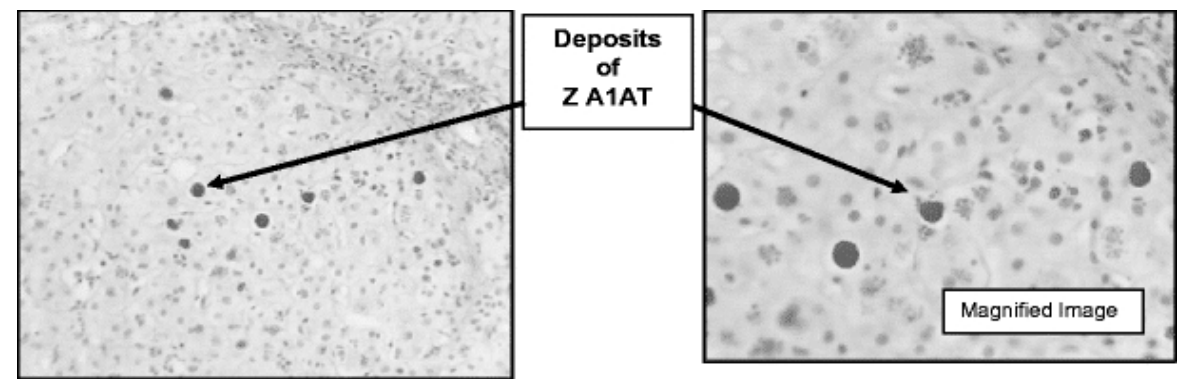

Fig. 3. Diastase-resistant periodic acid-Schiff stained liver section from a ZA1AT-deficient individual showing A1AT deposits.

(Fig. 3). In PiZZ individuals, 10-15\% show clinically significant liver disease in their first 20 years of life [30].

Hepatic disease associated with A1AT deficiency is most common in children. Of the 127 newborn PiZZ infants studied by Sveger et al. [31], all showed increased liver enzyme concentrations. Eleven percent had prolonged neonatal jaundice (the most common presentation of AAT deficiency in early childhood), of whom $29 \%$ developed cirrhosis. Sveger et al. [31] also showed that infants with a PiSZ phenotype had no signs of liver disease. A follow-up study [30] performed at age 16 of neonates screened in Sweden showed elevated liver enzymes in $17 \%$ of PiZZ and $8 \%$ of PiSZ adolescents. Adults with liver disease in infancy were later clinically healthy [30].

In adults, liver damage can manifest as chronic liver disease or hepatocellular carcinoma with reported incidences of the latter ranging from 5-30\% [30,32]. Five to ten percent of AAT-deficient patients over 50 will develop cirrhosis. A study of 19 adult patients with AAT deficiency and chronic liver disease revealed a late onset of symptomatic hepatic abnormalities. Thirteen patients $(68 \%)$ were 60 years or older when the liver disease was discovered. Mean age of the patients with the PiZZ, PiSZ, and PiMZ phenotypes were 58,66 , and 72.5 years when liver disease was diagnosed, suggesting later onset liver disease in heterozygotes [33].

\section{Other clinical manifestations of AAT deficiency}

An association has been described with Wegener's granulomatosis which is not surprising given that anti-neutrophil cytoplasmic antibody; the hallmark of this condition is raised against proteinase 3 which is naturally inhibited by AAT. There exists several case series [34,35] describing an excess of AAT phenotypes in cohorts with ANCA positive vasculitis. Necrotizing panniculitis is the characteristic skin lesion described in AAT deficiency. Clinical responses to augmentation therapy and dapsone have been described [36-38].

Reports of aneurysms (intra-cranial/abdominal) and fibromuscular dysplasia demonstrating predilections for AAT deficient patients exist [39] but formal association remains unproven. Renal disease has been implicated in AAT deficiency, 
with a heterogenous series of manifestations ranging from IgA nephropathy to membranoproliferative glomerulonephritis. There is also a reported association with the development of renal disease in patients with cirrhosis [40,41].

\section{Current and future translational and therapeutic aspects to disease}

In 1987 Wewers et al. [42] demonstrated that plasma purified AAT could be safely administered by intravenous infusion to AAT deficient individuals maintaining plasma levels above a putative protective threshold of $11 \mu \mathrm{m}$. This protective level was based on typical levels of AAT in SZ individuals, who if non-smokers are at minimal risk of developing emphysema [43]. Additionally, there were concomitant increases in both AAT and anti-NE capacity on the lung's epithelial surfaces. This evidence of biochemical efficacy is as yet unaccompanied by evidence of clinical efficacy. A number of studies suggest that intravenous AAT augmentation therapy may have some beneficial clinical effects. Seersholm et al. [44] compared a group of Danish exsmokers with AAT deficiency to a similar German group who received augmentation therapy. In individuals with forced expired volume in one second (FEV1) ranging from 31-65\% predicted there was a significant difference in FEV1 decline of approximately $21 \mathrm{cc} / y e a r$ between those receiving augmentation therapy and those who did not. Similar results were found on evaluation of the NHLBI registry data [45]. These data additionally showed a mortality risk reduction in those receiving AAT augmentation therapy. Further work by Dirksen et al. [46] evaluated radiographic changes $(\mathrm{CT})$ in those receiving augmentation therapy and although no significant difference $(p=0.07)$ was observed the study provided adequate information to develop a power statistic and determine how many AAT individuals were needed in future trials to conclusively show a clinical effect by CT scan. Consequently, spirometry measurements are now regarded as secondary efficacy endpoints. Once monthly and bi-weekly administration of AAT has also been evaluated but most data presently supports a once-weekly regimen [47].

Worries about potential transmission of infectious agents by a human plasmaderived product have led to the development of transgenic and recombinant sources of human AAT. Transgenic production of human AAT protein has been achieved in goats [48] and sheep [49], and human AAT has also been produced in yeast using recombinant technology [50]. Unfortunately, all these proteins are cleared more rapidly than plasma purified AAT from the circulation following intravenous administration. Consequently, the inhaled route has been investigated for these products. These have an acceptable half-life on the epithelial surface following aerosolisation. The conceptual concern with this route is that while it can be argued that increasing the level of AAT in blood and subsequently measuring it in epithelial lining fluid (ELF) gives some reassurance that the interstitium of the lung is being protected the same argument is not necessarily applicable with aerosolisation. A number of gene therapeutics for AAT deficiency has been developed. For example, 
the normal AAT gene has been successfully introduced into striated muscle cells in animals using an adeno-associated virus vector [51] but clinical trials are awaited.

In terms of hepatic manifestations, liver transplantation provides the only effective intervention. Liver transplantation achieves successful serum conversion and acceptable survival rates of over $80 \%$ in both adults and children. Its benefit and application is hampered by the lack of donors and negative aspects of life-long immunosuppressive therapy. With regards potential medical interventions Miller et al. [17] have shown that the bile acid tauroursodeoxycholic acid (TUDCA) targets the newly delineated apoptotic pathway in the liver and as such may hold therapeutic promise in promoting survival of hepatocytes in Z AAT expressing cells.

\section{Key challenges and opportunities faced by AATD patients worldwide}

There are a number of major questions, challenges and opportunities facing AAT deficient patients worldwide and these include;

1. What is the natural history of the condition?

2. How to diagnose individuals before appreciable organ damage?

3. How to determine whether current treatment modalities are effective and if not to investigate more effective therapeutics?

4. How to determine whether MZ carriers are at increased risk of lung disease?

5. How to utilise lessons from over 50 years research in AAT deficiency to better understand the pathogenesis of non-AAT related lung and liver disease?

\subsection{The natural history of AAT deficiency}

The natural history of this condition still requires elucidation. We do not know how many people there are with the condition and how many will be clinically affected if they do not smoke or have other significant liver disease. Most published data suggesting a bleak outcome are based mainly on symptomatic index cases [52]. With new larger pan-national registries and targeted detection programs inclusive of studying family members, a clearer picture should emerge in the coming decades.

\subsection{Diagnoses of individuals before appreciable organ damage}

This has been a major problem particularly in the early years of the condition. The diagnostic algorithms for lung disease have tested individuals with obstruction at an early age. The new diagnostic algorithms widen the net considerably (Table 2) to include first degree relatives, poorly responsive asthmatics, and individuals with cryptogenic cirrhosis and vasculitis, inevitably leading to earlier detection rates. 
Table 2

Guidelines for diagnostic testing of AAT deficiency (adapted from ATS AAT Task Force Recommendations); A: Genetic testing is recommended B: Genetic testing should be discussed and could reasonably be accepted or declined

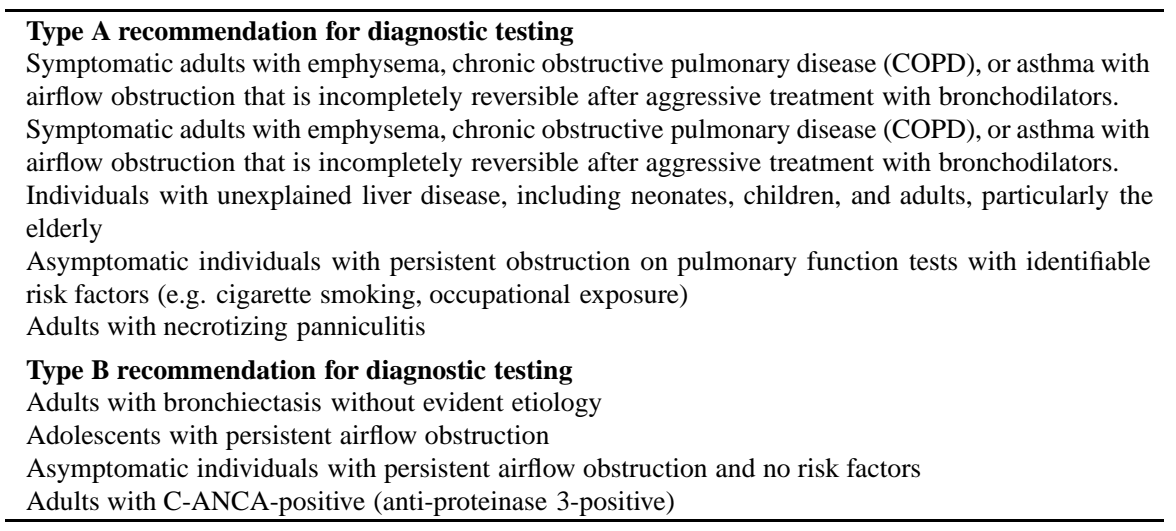

\subsection{Determine efficacy of current treatments}

We are still uncertain whether augmentation therapy has any clinical effect. This disappointing fact, twenty years after the original Wewers et al. paper [41] is not surprising given the numbers of patients who would have to be studied to prove efficacy. It is estimated that approximately 550 AAT deficient individuals would need to be studied over a 2 year period to show a significant impact of intravenous AAT augmentation therapy on spirometry. However only 130 would have to be studied to show impacts on CT based indices of emphysema. This has been one of the major breakthroughs in recent years and such parameters are now accepted by the Food and Drugs Administration (FDA) [53].

\subsection{Are MZ carriers at increased risk of disease manifestations?}

Many studies of the PI MZ population and COPD risk have been performed with inconsistent results. In general, studies comparing COPD with healthy controls have found an excess of PI MZ individuals among COPD cases, but studies assessing FEV1 in PI MZ and PI MM subjects from population-based samples have not found significant differences [54]. Our group in collaboration is currently assessing this question. We are performing this in the setting of National Registries and in specific studies utilising the MZ population detected by our targeted detection program.

\subsection{Utilise lessons from over 50 years of research to understand the pathogenesis of non-AAT related lung and liver disease}

AAT deficiency is the only hereditary condition directly related to development of COPD. As such it gives invaluable insight into COPD pathogenesis and its treatment. This deficiency has inspired studies into the effects of oxidants from cigarette 
smoke [55-58] and their ability to inactivate normal M AAT causing a functional deficiency in the lungs of smokers [59]. This suggests possible therapeutic options such as antiproteases or antioxidants. While hepatic manifestations have been less studied many of the mechanisms elucidated in AAT liver disease can be applied to other conditions such as viral liver disease and haemachromatosis. Most recently our understanding of AAT deficiency as a conformational disorder has paved the way to a better understanding of pathogenesis of conditions as disparate as Alzheimer's, Parkinson's and Huntington's disease.

\section{Examples of physician initiatives in the EU and/or internationally}

There have been increasing numbers of physician-inspired initiatives within the realm of AATD in the last decade. For example within the European Union several augmentation and lung transplant programmes exist along with the alpha-1 international registry (AIR). The Alpha One Foundation and the University of Florida screening programmes in the United States provide further evidence of this trend. For the purposes of this chapter, we will highlight our national targeted initiative that has been developed over the last five years: "The National Alpha-1 Antitrypsin Deficiency Targeted Detection Programme and Registry".

In the Republic of Ireland, we established in 2004 a national targeted detection programme for suspected alpha- 1 antitrypsin deficiency patients and a website (http://www.alpha1.ie/) that provides a resource for physicians, patients and the general public.

This programme is directly funded by the Department of Health and provides testing for AAT deficiency at no cost to patients at risk according to ATS guidelines.

Based on a genetic screening study on 1000 random samples by our group, we estimate that 3,000 Irish citizens have the deficiency and up to 700,000 are carriers, yet only a fraction of these has been identified to date. The targeted detection program is into its fifth operational year and during the period we have tested 3,000 individuals throughout Ireland. Thus far, we have identified over 90 severely deficient individuals (ZZ, SZ) and over 700 moderately deficient individuals (carriers, mainly MZ).

Following diagnosis, the foundation provides multiple ancillary services to patients including counselling, expert advice through clinics, information packs and leaflets for patients and relatives. Through this initiative, we also offer patients opportunities for enrolment in clinical trials including an augmentation therapy trial and membership of the alpha-1 patient support group. In the last year, we have established a National Alpha-1 Registry to track the health status of patients with the deficiency throughout Ireland. The type of information collected includes height, weight, gender, genotype, pulmonary function, liver tests, hospitalisations and complications related to lung and liver disease manifestations. Such information will help clinicians and researchers to identify new trends, design clinical trials and improve care delivery for patients. 


\section{Conclusion}

Alpha-1 antitrypsin deficiency is more prevalent in Ireland than was previously thought, even after making allowances for the targeted symptomatic population investigated through our national initiatives. The importance of an early and accurate diagnosis cannot be over-emphasised as the consequential medical follow-up and lifestyle changes help to prevent or at least postpone the development of related lung and liver disease.

\section{References}

[1] C.B. Laurell, ES. The electrophoretic alpha 1-globulin pattern of serum in alpha 1-antitrypsin deficiency, Scand J Clin Lab Invest 15 (1963), 132-140.

[2] H.L. Sharp, R.A. Bridges, W. Krivit and E.F. Freier, Cirrhosis associated with alpha-1-antitrypsin deficiency: a previously unrecognized inherited disorder, J Lab Clin Med 73(6) (Jun 1969), 934939.

[3] M.C. Owen, S.O. Brennan, J.H. Lewis and R.W. Carrell, Mutation of antitrypsin to antithrombin. alpha 1-antitrypsin Pittsburgh (358 Met leads to Arg), a fatal bleeding disorder, $N$ Engl J Med 309(12) (22 Sep 1983), 694-698.

[4] F.J. de Serres, Worldwide racial and ethnic distribution of alpha1-antitrypsin deficiency: summary of an analysis of published genetic epidemiologic surveys, Chest 122(5) (Nov 2002), 1818-1829.

[5] D.C. Hutchison, Alpha 1-antitrypsin deficiency in Europe: geographical distribution of Pi types S and Z, Respir Med 92(3) (Mar 1998), 367-377.

[6] D.T. Curiel, A. Chytil, M. Courtney and R.G. Crystal, Serum alpha 1-antitrypsin deficiency associated with the common S-type (Glu264_-Val) mutation results from intracellular degradation of alpha 1-antitrypsin prior to secretion, J Biol Chem 264(18) (25 Jun 1989), 10477-10486.

[7] D.A. Lomas, D.L. Evans, J.T. Finch and R.W. Carrell, The mechanism of Z alpha 1-antitrypsin accumulation in the liver, Nature 357(6379) (18 Jun 1992), 605-607.

[8] P.R. Elliott, D. Bilton and D.A. Lomas, Lung polymers in Z alpha1-antitrypsin deficiency-related emphysema, Am J Respir Cell Mol Biol 18(5) (May 1998), 670-674.

[9] S. Janciauskiene, R. Dominaitiene, N.H. Sternby, E. Piitulainen and S. Eriksson, Detection of circulating and endothelial cell polymers of $\mathrm{Z}$ and wild type alpha 1-antitrypsin by a monoclonal antibody, J Biol Chem 277(29) (19 Jul 2002), 26540-26546.

[10] A.T. Mulgrew, C.C. Taggart, M.W. Lawless, C.M. Greene, M.L. Brantly, S.J. O’Neill et al., Z alpha1-antitrypsin polymerizes in the lung and acts as a neutrophil chemoattractant, Chest $\mathbf{1 2 5}(5)$ (May 2004), 1952-1957.

[11] N.G. McElvaney, R.C. Hubbard, P. Birrer, M.S. Chernick, D.B. Caplan, M.M. Frank et al., Aerosol alpha 1-antitrypsin treatment for cystic fibrosis, Lancet 337(8738) (16 Feb 1991), 392-394.

[12] M.F. Tosi, H. Zakem and M. Berger, Neutrophil elastase cleaves C3bi on opsonized pseudomonas as well as CR1 on neutrophils to create a functionally important opsonin receptor mismatch, J Clin Invest 86(1) (Jul 1990), 300-308.

[13] R.B. Fick, Jr., G.P. Naegel, S.U. Squier, R.E. Wood, J.B. Gee and H.Y. Reynolds, Proteins of the cystic fibrosis respiratory tract. Fragmented immunoglobulin $\mathrm{G}$ opsonic antibody causing defective opsonophagocytosis, J Clin Invest 74(1) (Jul 1984), 236-248.

[14] L.A. Smallman, S.L. Hill and R.A. Stockley, Reduction of ciliary beat frequency in vitro by sputum from patients with bronchiectasis: a serine proteinase effect, Thorax 39(9) (Sep 1984), 663-667.

[15] N. Guyot, M.W. Butler, P. McNally, S. Weldon, C.M. Greene, R.L. Levine et al., Elafin, an elastasespecific inhibitor, is cleaved by its cognate enzyme neutrophil elastase in sputum from individuals with cystic fibrosis, J Biol Chem 283(47) (21 Nov 2008), 32377-32385. 
[16] C.C. Taggart, G.J. Lowe, C.M. Greene, A.T. Mulgrew, S.J. O’Neill, R.L. Levine et al., Cathepsin B, L, and S cleave and inactivate secretory leucoprotease inhibitor, J Biol Chem 276(36) (7 Sep 2001), 33345-33352.

[17] S.D. Miller, C.M. Greene, C. McLean, M.W. Lawless, C.C. Taggart, S.J. O'Neill et al., Tauroursodeoxycholic acid inhibits apoptosis induced by $\mathrm{Z}$ alpha-1 antitrypsin via inhibition of Bad, Hepatology 46(2) (Aug 2007), 496-503.

[18] S. Eriksson, Pulmonary emphysema and alpha1-antitrypsin deficiency, Acta Med Scand 175 (1964), 197 (Manual).

[19] P. Gishen, A.J. Saunders, M.J. Tobin and D.C. Hutchison, Alpha 1-antitrypsin deficiency: the radiological features of pulmonary emphysema in subjects of Pi type Z and Pi type SZ: a survey by the British Thoracic Association, Clin Radiol 33(4) (Jul 1982), 371-377.

[20] M.L. Brantly, L.D. Paul, B.H. Miller, R.T. Falk, M. Wu and R.G. Crystal, Clinical features and history of the destructive lung disease associated with alpha-1-antitrypsin deficiency of adults with pulmonary symptoms, Am Rev Respir Dis 138(2) (Aug 1988), 327-336.

[21] C. Larsson, Natural history and life expectancy in severe alpha1-antitrypsin deficiency, Pi Z, Acta Med Scand 204(5) (1978), 345-351.

[22] S. Eriksson, Studies in alpha 1-antitrypsin deficiency, Acta Med Scand Suppl 432 (1965), 1-85.

[23] M.J. Tobin, P.J. Cook and D.C. Hutchison, Alpha 1 antitrypsin deficiency: the clinical and physiological features of pulmonary emphysema in subjects homozygous for Pi type Z. A survey by the British Thoracic Association, Br J Dis Chest 77(1) (Jan 1983), 14-27.

[24] E.D. Janus, N.T. Phillips and R.W. Carrell, Smoking, lung function, and alpha 1-antitrypsin deficiency, Lancet 1(8421) (19 Jan 1985), 152-154.

[25] N.G. McElvaney, J.K. Stoller, A.S. Buist, U.B. Prakash, M.L. Brantly, M.D. Schluchter et al., Baseline characteristics of enrollees in the National Heart, Lung and Blood Institute Registry of alpha 1-antitrypsin deficiency. Alpha 1-Antitrypsin Deficiency Registry Study Group, Chest 111(2) (Feb 1997), 394-403.

[26] N Seersholm and A Kok-Jensen Survival in relation to lung function and smoking cessation in patients with severe hereditary alpha 1-antitrypsin deficiency, Am J Respir Crit Care Med 151 (2 1995), 369-373.

[27] E. Eden, D. Mitchell, B. Mehlman, H. Khouli, M. Nejat, M.H. Grieco et al., Atopy, asthma, and emphysema in patients with severe alpha-1-antitrypysin deficiency, Am J Respir Crit Care Med 156(1) (Jul 1997), 68-74.

[28] P.J. Guest and D.M. Hansell, High resolution computed tomography (HRCT) in emphysema associated with alpha-1-antitrypsin deficiency, Clin Radiol 45(4) (Apr 1992), 260-266.

[29] M.A. King, J.A. Stone, P.T. Diaz, C.F. Mueller, W.J. Becker and J.E. Gadek, Alpha 1-antitrypsin deficiency: evaluation of bronchiectasis with CT, Radiology 199(1) (Apr 1996), 137-141.

[30] T. Sveger and S. Eriksson, The liver in adolescents with alpha 1-antitrypsin deficiency, Hepatology 22(2) (Aug 1995), 514-517.

[31] T. Sveger, Liver disease in alpha1-antitrypsin deficiency detected by screening of 200,000 infants, N Engl J Med 294(24) (10 Jun 1976), 1316-1321.

[32] S. Eriksson, Alpha 1-antitrypsin deficiency and liver cirrhosis in adults. An analysis of 35 Swedish autopsied cases, Acta Med Scand 221(5) (1987), 461-467.

[33] J. Rakela, M. Goldschmiedt and J. Ludwig, Late manifestations of chronic liver disease in adults with alpha 1-antitrypsin deficiency, Dig Dis Sci 32(12) (Dec 1987), 1358-1362.

[34] J.A. Savige, L. Chang, L. Cook, J. Burdon, M. Daskalakis and J. Doery, Alpha 1-antitrypsin deficiency and anti-proteinase 3 antibodies in anti-neutrophil cytoplasmic antibody (ANCA)-associated systemic vasculitis, Clin Exp Immunol 100(2) (May 1995), 194-197.

[35] V.L. Esnault, A. Testa, M. Audrain, C. Roge, M. Hamidou, J.H. Barrier et al., Alpha 1-antitrypsin genetic polymorphism in ANCA-positive systemic vasculitis, Kidney Int 43(6) (Jun 1993), 13291332.

[36] P. Geraminejad, J.R. DeBloom 2nd, H.W. Walling, R.D. Sontheimer and M. VanBeek, Alpha1-antitrypsin associated panniculitis: the MS variant, J Am Acad Dermatol 51(4) (Oct 2004), 645-655. 
[37] M.R. Pittelkow, K.C. Smith and W.P. Su, Alpha-1-antitrypsin deficiency and panniculitis. Perspectives on disease relationship and replacement therapy, Am J Med 84(6A) (24 Jun 1988), 80-86.

[38] B.K. Edmonds, J.A. Hodge and R.L. Rietschel, Alpha 1-antitrypsin deficiency-associated panniculitis: case report and review of the literature, Pediatr Dermatol 8(4) (Dec 1991), 296-299.

[39] W.I. Schievink, M.R. Puumala, F.B. Meyer, C. Raffel, J.A. Katzmann and J.E. Parisi, Giant intracranial aneurysm and fibromuscular dysplasia in an adolescent with alpha 1-antitrypsin deficiency, $J$ Neurosurg 85(3) (Sep 1996), 503-506.

[40] I.D. Davis, B. Burke, D. Freese, H.L. Sharp and Y. Kim, The pathologic spectrum of the nephropathy associated with alpha 1-antitrypsin deficiency, Hum Pathol 23(1) (Jan 1992), 57-62.

[41] G. Noble-Jamieson, S. Thiru, P. Johnston, P. Friend and N.D. Barnes, Glomerulonephritis with end-stage liver disease in childhood, Lancet 339(8795) (21 Mar 1992), 706-707.

[42] M.D. Wewers, M.A. Casolaro, S.E. Sellers, S.C. Swayze, K.M. McPhaul, J.T. Wittes et al., Replacement therapy for alpha 1-antitrypsin deficiency associated with emphysema, $N$ Engl J Med 316(17) (23 Apr 1987), 1055-1062.

[43] R.G. Crystal, Alpha-1-antitrypsin deficiency, emphysema and liver disease: genetic basis and strategies for therapy, J Clin Invest 85 (1990), 1343-1352.

[44] N. Seersholm, M. Wencker, N. Banik, K. Viskum, A. Dirksen, A. Kok-Jensen et al., Does alpha1antitrypsin augmentation therapy slow the annual decline in FEV1 in patients with severe hereditary alpha1-antitrypsin deficiency? Wissenschaftliche Arbeitsgemeinschaft zur Therapie von Lungenerkrankungen (WATL) alpha1-AT study group, Eur Respir J 10(10) (Oct 1997), 2260-2263.

[45] Survival and FEV1 decline in individuals with severe deficiency of alpha1-antitrypsin. The Alpha1-Antitrypsin Deficiency Registry Study Group, Am J Respir Crit Care Med 158(1) (Jul 1998), 49-59.

[46] A. Dirksen, J.H. Dijkman, F. Madsen, B. Stoel, D.C. Hutchison, C.S. Ulrik et al., A randomized clinical trial of alpha(1)-antitrypsin augmentation therapy, Am J Respir Crit Care Med 160(5 Pt 1) (Nov 1999), 1468-1472.

[47] M. Wencker, N. Banik, R. Buhl, R. Seidel and N. Konietzko, Long-term treatment of alpha1-antitrypsin deficiency-related pulmonary emphysema with human alpha1-antitrypsin. Wissenschaftliche Arbeitsgemeinschaft zur Therapie von Lungenerkrankungen (WATL)-alpha1-ATstudy group, Eur Respir J 11(2) (Feb 1998), 428-433.

[48] C.A. Ziomek, Commercialization of proteins produced in the mammary gland, Theriogenology 49(1) (1 Jan 1998), 139-144.

[49] G. Wright, A. Carver, D. Cottom, D. Reeves, A. Scott, P. Simons et al., High level expression of active human alpha-1-antitrypsin in the milk of transgenic sheep, Biotechnology $(N Y)$ 9(9) (Sep 1991), 830-834.

[50] M.A. Casolaro, G. Fells, M. Wewers, J.E. Pierce, F. Ogushi, R. Hubbard et al., Augmentation of lung antineutrophil elastase capacity with recombinant human alpha-1-antitrypsin, J Appl Physiol 63(5) (Nov 1987), 2015-2023.

[51] T.M. Kolodka, M. Finegold, M.A. Kay and S.L. Woo, Hepatic gene therapy: efficient retroviralmediated gene transfer into rat hepatocytes in vivo, Somat Cell Mol Genet 19(5) (Sep 1993), 491-497.

[52] T. Sveger, E. Piitulainen, M. Arborelius, Jr., Lung function in adolescents with alpha 1-antitrypsin deficiency, Acta Paediatr 83(11) (Nov 1994), 1170-1173.

[53] Proceedings of Meeting of Blood and Plasma Advisory Committee. Federal Drug Administration, Rockville, Maryland, 1998.

[54] C.P. Hersh, M. Dahl, N.P. Ly, C.S. Berkey, B.G. Nordestgaard and E.K. Silverman, Chronic obstructive pulmonary disease in alpha1-antitrypsin PI MZ heterozygotes: a meta-analysis, Thorax 59(10) (Oct 2004), 843-849.

[55] I. Rahman and W. MacNee, Oxidant/antioxidant imbalance in smokers and chronic obstructive pulmonary disease, Thorax 51(4) (Apr 1996), 348-350.

[56] J.C. Taylor, R. Madison and D. Kosinska, Is antioxidant deficiency related to chronic obstructive pulmonary disease? Am Rev Respir Dis 134(2) (Aug 1986), 285-289. 
[57] W.A. Pryor and K. Stone, Oxidants in cigarette smoke. Radicals, hydrogen peroxide, peroxynitrate, and peroxynitrite, Ann N Y Acad Sci 686 (28 May 1993), 12-27; discussion -8.

[58] T. Nakayama, D.F. Church and W.A. Pryor, Quantitative analysis of the hydrogen peroxide formed in aqueous cigarette tar extracts, Free Radic Biol Med 7(1) (1989), 9-15.

[59] R.C. Hubbard, F. Ogushi, G.A. Fells, A.M. Cantin, S. Jallat, M. Courtney et al., Oxidants spontaneously released by alveolar macrophages of cigarette smokers can inactivate the active site of alpha 1-antitrypsin, rendering it ineffective as an inhibitor of neutrophil elastase, J Clin Invest $\mathbf{8 0}(5)$ (Nov 1987), 1289-1295. 